\title{
Early Systemic Cellular Immune Response in Children and Young Adults Receiving Decellularized Fresh Allografts for Pulmonary Valve Replacement
}

\author{
Anneke Neumann, MD, ${ }^{1, \star}$ Samir Sarikouch, MD, PhD, ${ }^{1, *}$ Thomas Breymann, MD, ${ }^{1}$ Serghei Cebotari, MD, \\ Dietmar Boethig, MD, PhD, ${ }^{2}$ Alexander Horke, MD, ${ }^{1}$ Philipp Beerbaum, MD, PhD, ${ }^{2}$ \\ Mechthild Westhoff-Bleck, MD, ${ }^{3}$ Harald Bertram, MD, PhD, ${ }^{2}$ Masamichi Ono, MD, PhD, ${ }^{1}$ \\ Igor Tudorache, MD, ${ }^{1}$ Axel Haverich, MD, PhD, and Gernot Beutel, MD ${ }^{4}$
}

Objectives: The longevity of homografts is determined by the activation of the recipients' immune system resulting from allogenic antigen exposition. Fresh decellularized pulmonary homografts (DPH) have shown promising early results in pulmonary valve replacement in children and young adults and could potentially avoid significant activation of the immune system, as more than $99 \%$ of the donor DNA is removed during the decellularization process. While the humoral immune response to decellularized allografts has been studied, detailed information on the more significant cellular immune response is currently lacking.

Methods and Results: Peripheral blood samples were obtained from patients undergoing pulmonary valve replacement with DPH before, after, and for approximately 3 years after implantation. Absolute counts and percentages of mature T- $\left(\mathrm{CD}^{+}\right)$, B- $\left(\mathrm{CD} 19^{+}\right)$, and natural killer- $\left(\mathrm{CD} 16^{+} / \mathrm{CD} 56^{+}\right)$cells, as well as T helper$\left(\mathrm{CD}^{+}\right)$and cytotoxic T-cell- $\left(\mathrm{CD} 8^{+}\right)$subsets, were determined by fluorescence-activated cell sorting (FACS). Between May 2009 and September 2013, 199 blood samples taken from 47 patients with a mean age at DPH implantation of $16.6 \pm 10.8$ years were analyzed. The hemodynamic performance of DPH was excellent in all but one patient, and no valve-related deaths or conduit explantations were observed. The short-term follow up revealed a significant postoperative decrease in cell counts of most subtypes with reconstitution after 3 months. Continued assessment did not show any significant deviations in cell counts from their baseline values.

Conclusion: The absence of cellular immune response in patients receiving DPH supports the concept that decellularization can provide a basis for autologous regeneration.

\section{Introduction}

S INCE THE BEGINNING of heart valve surgery, research has focused on the development of the ideal heart valve prosthesis. The most important requirements are lack of thrombogenicity, resistance to infections, and unlimited durability. ${ }^{1,2}$ These days, most heart valve prostheses are either mechanical or of xenogenic origin ("biological" valves).

Since the implantation of a mechanical valve carries a higher thromboembolic risk and requires lifelong anticoagulation therapy with potentially inherent complications, ${ }^{3}$ biological valves of xenogenic origin or human cryopreserved allografts are preferred especially for younger patients or in the pediatric population. ${ }^{4}$ However, both types have a limited durability due to calcification, ${ }^{5}$ which is mainly driven by immunological-inflammatory processes that are triggered by viable preserved "foreign" donor cells in the xenograft/allograft valvular tissue. ${ }^{6}$ Due to the fact that infants and children show stronger immunologic reactions to these grafts, re-interventions are needed at an earlier stage than in adult patients. ${ }^{7,8}$

Detergent decellularization, a process enabling an almost complete removal of all cells and cellular debris (>99\%) without affecting the extracellular matrix (ECM), provides a promising approach. ${ }^{9}$ It results in a theoretically less antigenic valvular matrix, which has been shown to be repopulated by viable autologous interstitial and endothelial cells after implantation in vivo, thus displaying potential for enhanced durability. ${ }^{10-14}$

This approach has been applied to allogenic as well as the more readily available xenogenic valves. Unfortunately, implanted decellularized xenogenic valves degenerated

Departments of ${ }^{1}$ Cardiothoracic, Transplantation, and Vascular Surgery, ${ }^{2}$ Pediatric Cardiology and Intensive Care Medicine, ${ }^{3}$ Cardiology and Angiology, and ${ }^{4}$ Hematology, Hemostasis, Oncology, and Stem Cell Transplantation, Hannover Medical School, Hannover, Germany.

*These authors contributed equally to this work. 
rapidly in a number of pediatric patients, who subsequently suffered from dramatic graft failure. A potential reason for the immunogenicity may lie in the xenogenic matrix itself. Accordingly, explanted grafts showed a severe foreign body reaction that is associated with a severe inflammatory reaction, exaggerated fibrotic scarring, and neo-intima formation. ${ }^{15,16}$

Recently, we reported early clinical results on the implantation of fresh decellularized pulmonary homografts (DPH) compared with glutaraldehyde-fixed bovine jugular veins and cryopreserved homografts in children and young adults. During the follow-up period of up to 5 years, DPH showed improved freedom from explantation, low transvalvular gradients, and adaptive growth. ${ }^{11,17,18}$ Since decellularized human valve allografts consist of ECM with a negligible amount of remaining donor cells, they should not trigger an immune response to the allograft. In contrast to several existing studies addressing the question of a humoral immune response to cryopreserved decellularized allografts, ${ }^{19-21}$ data on the cellular immune response are lacking to date. The cell-mediated immune response, however, is one leading factor for rapid structural implant deterioration. ${ }^{22,23}$ Therefore, the aim of our study was to evaluate whether the implantation of a fresh DPH elicits a cellular immune response in children and young adults.

\section{Materials and Methods}

\section{Study cohort}

Sixty-nine pediatric and adult patients have so far received a DPH for pulmonary valve replacement at Hannover Medical School, Germany, and in the State Medical and Pharmaceutical University Hospital, Chisinau, Moldova. Details of the decellularization protocol and the implantation procedure have been provided elsewhere. ${ }^{11}$

From this cohort, 47 consecutive patients, operated on between May 2009 and July 2012 at Hannover Medical School, underwent blood sampling in addition to their regular follow-up investigations, which included a clinical examination, echocardiography, and cardiac magnetic resonance imaging.

Peripheral blood samples were taken before and at hospital discharge after pulmonary valve replacement, at the 3 and 6 months follow up, and, subsequently, every 6-12 months. All patients or parents provided written informed consent, and the study was approved by the local institutional ethics committee (No. 528/2009).

\section{Cellular immune response}

The absolute numbers of leukocytes and lymphocytes, as well as the absolute numbers and percentages of $\mathrm{T}-\left(\mathrm{CD} 3^{+}\right)$, $\mathrm{T}$ helper- $\left(\mathrm{CD} 4^{+}\right)$, cytotoxic $\mathrm{T}-\left(\mathrm{CD} 8^{+}\right), \mathrm{B}-\left(\mathrm{CD} 19^{+}\right)$, and natural killer $(\mathrm{NK})$ - cells $\left(\mathrm{CD} 16^{+} \mathrm{CD} 56^{+}\right)$were determined by multi-color flow cytometry using a fluorescenceactivated cell sorting system (FACS Canto II; BD Biosciences, San Jose, CA). According to the manufacturer's instructions, fresh whole blood samples were stained with monoclonal antibodies (mAbs) that were directly conjugated with different fluorochromes (BD Multitest TBNK reagent; BD Biosciences Pharmingen, San Jose, CA). The following anti-
Table 1. Description of Patient Cohorts

\begin{tabular}{|c|c|c|}
\hline & $\begin{array}{c}\text { No } \\
\text { immunological } \\
\text { monitoring } \\
(\mathrm{n}=22)\end{array}$ & $\begin{array}{l}\text { Immunological } \\
\text { monitoring } \\
(\mathrm{n}=47)\end{array}$ \\
\hline Implantation period & 2005 to 2013 & 2009 to 2013 \\
\hline \multicolumn{3}{|l|}{ Diagnoses } \\
\hline DORV & 1 & 1 \\
\hline PA/IVS & 1 & 3 \\
\hline PA_VSD & 0 & 2 \\
\hline $\mathrm{PI} / \mathrm{PS}$ & 5 & 5 \\
\hline Ross & 4 & 5 \\
\hline TAC & 1 & 0 \\
\hline TGA & 1 & 2 \\
\hline TOF & 8 & 29 \\
\hline Total & 22 & 47 \\
\hline $\begin{array}{l}\text { Mean age at } \\
\text { implantation, } y\end{array}$ & $12.2 \pm 8.7$ & $16.6 \pm 10.8$ \\
\hline Mean follow-up, y & $4.9 \pm 2.4$ & $2.5 \pm 1.0$ \\
\hline Total follow-up, y & 107.3 & 116.9 \\
\hline Sex, male & $12(54.6 \%)$ & $31(66.0 \%)$ \\
\hline \multicolumn{3}{|l|}{$\begin{array}{l}\text { No. of previous } \\
\text { operations }\end{array}$} \\
\hline 0 & 10 & 2 \\
\hline 1 & 8 & 28 \\
\hline 2 & 1 & 13 \\
\hline$>2$ & 3 & 4 \\
\hline \multicolumn{3}{|l|}{$\begin{array}{l}\text { Type of previous } \\
\text { procedures }\end{array}$} \\
\hline None & 11 & 2 \\
\hline Homograft & 1 & 10 \\
\hline Valved conduit & 2 & 3 \\
\hline Bovine jugular vein & 1 & 4 \\
\hline $\begin{array}{l}\text { Transcatheter } \\
\text { pulmonary valve }\end{array}$ & 0 & 1 \\
\hline Unvalved Dacron tube & 1 & 2 \\
\hline $\begin{array}{l}\text { Catheter-based } \\
\text { intervention }\end{array}$ & 2 & 12 \\
\hline Open valvulotomy & 2 & 1 \\
\hline $\begin{array}{l}\text { Extracardiac palliation, } \\
\text { as BT shunt }\end{array}$ & 1 & 4 \\
\hline $\begin{array}{l}\text { Intracardiac repair, } \\
\text { as RVOT patch }\end{array}$ & 7 & 28 \\
\hline \multicolumn{3}{|l|}{ Conduit diameter, $\mathrm{mm}$} \\
\hline $12-19$ & 7 & 4 \\
\hline $20-23$ & 9 & 16 \\
\hline $24-32$ & 6 & 27 \\
\hline
\end{tabular}

DORV, double-outlet right ventricle; PA/IVS, pulmonary atresia with intact ventricular septum; PA/VSD, pulmonary atresia with ventricular septal defect; PI/PS, pulmonary stenosis and/or insufficiency; TAC, truncus arteriosus communis; TGA, transposition of the great arteries; TOF, tetralogy of Fallot; and RVOT, right ventricular outflow tract; BT, Blalock-Taussig.

human mAbs were used: FITC-labeled CD3, PE-labeled CD16 and CD56, PerCp-Cy 5.5-labeled CD45, PE-Cy7labeled CD4, APC-labeled CD19, and APC-Cy7-labeled CD8.

\section{Statistical analyses}

An intraindividual assessment for changes in the number of total white blood cells, lymphocytes, as well as the number and percentage of lymphocyte subsets was 

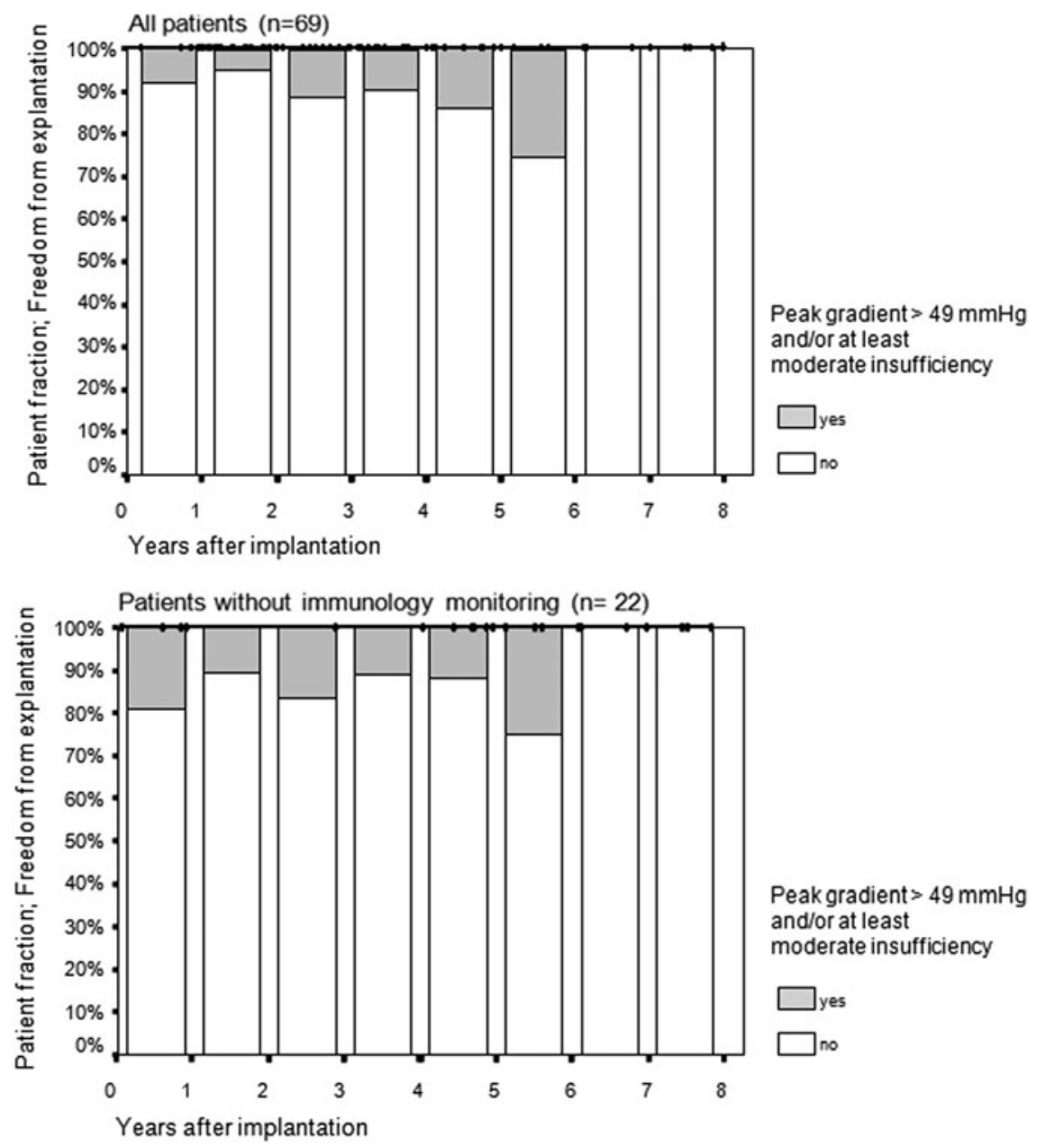

FIG. 1. Freedom from explantation and hemodynamic performance of fresh decellularized pulmonary homografts (DPH). The y-axis shows the percentage of patients free from conduit explantation. Small black bars at the top of the respective columns represent each patient examined at the latest follow-up year indicated at the $\mathrm{x}$-axis. The top graphic shows the hemodynamic data of all 69 patients who received a DPH from 2005 to 2012, the central graphic outlines the results of the 22 patients without immunological data, and the bottom graphic indicates the results of the 47 patients with immunological monitoring. Gray areas within the respective year column indicate impaired valve function defined by a transvalvular peak gradient $>49 \mathrm{mmHg}$ and/or at Patients with immunology monitoring $(n=47)$

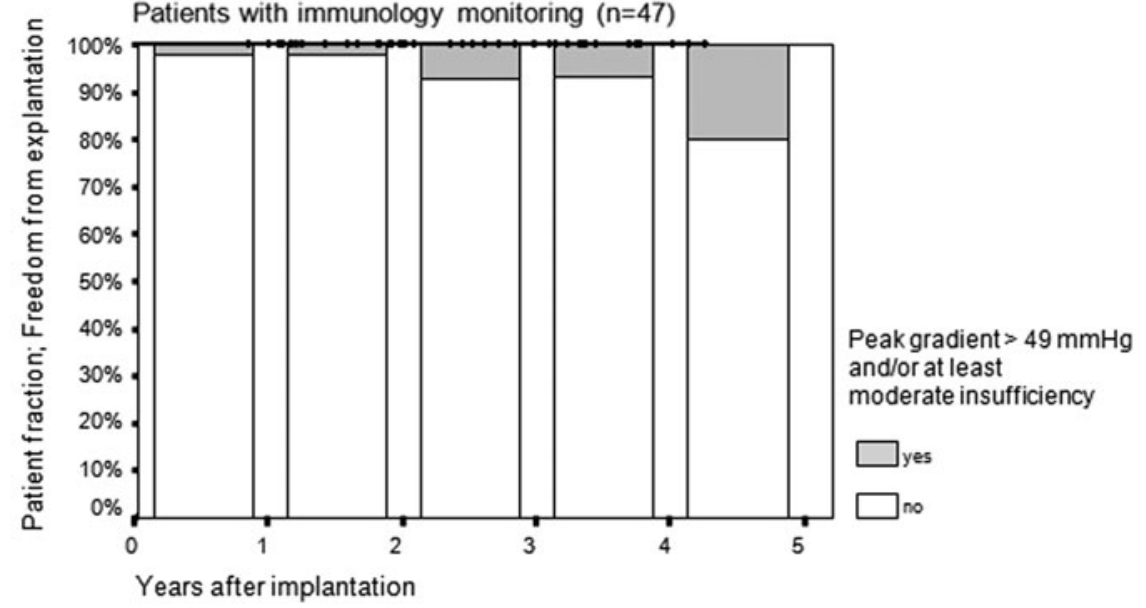
least moderate insufficiency.

performed using a paired $t$-test. Two sided $p$-values of $<0.05$ were considered statistically significant. Potential timedependent effects were evaluated by analyzing measurements across the whole study cohort at every given time point. Furthermore, a linear regression model was fitted to evaluate potential links between valvular gradients and cell numbers.

Statistical analyses were performed using R-Project (software version 2.10.1 for Linux). DPH performance is shown as a fraction of degenerated conduits below the
Kaplan-Meier curve for freedom from explantation (IBM SPSS Statistics 20, Ehningen, Germany).

\section{Results \\ Patients}

To date, 69 pediatric and adult patients received fresh, non-cell seeded decellularized homografts for pulmonary valve replacement according to the Hannover protocol, starting in 2005. From this cohort, 47 consecutive patients 
with a mean age of $16.6 \pm 10.8$ years at implantation were analyzed for cellular immune response. In total, 199 blood samples were analyzed between May 2009 and September 2013.

For this group, the mean follow-up period was $2.5 \pm 1.0$ years and the total cumulative observation time was 81.75 years (981 months). Most of the patients $(n=28,60 \%)$ had undergone a previous heart operation, while 17 patients $(36 \%)$ had undergone two or more surgical interventions. Ten patients $(21 \%)$ had pulmonary valve replacement using a cryopreserved homograft before DPH. Twenty-seven patients (57\%) received a DPH with a diameter between 24 and $30 \mathrm{~mm}$. No patient received immunosuppressive medication.

For 22 patients, no immunological data were available, as they received a DPH before the start of the immunological monitoring in 2009 or because parental consent was not given. Detailed information on the study cohort, including underlying cardiac malformation, the type and number of previous procedures, and implanted homograft diameters, is given in Table 1.

\section{Clinical course of DPH}

During a total observation time of more than 224 years, no patient developed a neoplasma, neither the incidence of viral or bacterial infections was increased.
At discharge, echocardiography showed low-pressure transvalvular gradients in all patients.

After 3 years of follow up, freedom from any signs of valve degeneration (defined as peak gradient $>49 \mathrm{mmHg}$ over any part of the conduit and/or at least moderate valve insufficiency) was $92 \%$ for the study cohort under immunological monitoring.

During the 8-year follow up of all patients, no DPH valve had to be explanted. There were no valve-related deaths. Two patients died during the follow up due to non-valverelated reasons: one in Moldava as previously reported ${ }^{11}$ and one 6-week-old infant who died in Hannover 9 weeks postoperatively due to fulminant sepsis in conjunction with persistent severe chylothorax. Figure 1 gives detailed information on the hemodynamic performance of DPH valves in patients both with and without immunological monitoring at different time points of follow up.

One patient developed moderate non-calcific conduit degeneration with a maximum valvular gradient of $54 \mathrm{mmHg}$ (mean gradient $27 \mathrm{mmHg}$ ) at 18 months after DPH implantation. He was successfully treated by balloon dilation, which reduced the peak gradient to $40 \mathrm{mmHg}$ (mean $23 \mathrm{mmHg}$ ). During a further 24 months of follow up, the gradient remained stable and no significant regurgitation was observed.
FIG. 2. Systemic cellular immune response during follow up-Part I. Absolute counts of leukocytes (A), lymphocytes (B), $\mathrm{CD}^{+}{ }^{+} \mathrm{T}$ cells $(\mathbf{C})$, and CD19 ${ }^{+}$B-cells (D) were measured before DPH implantation, directly postoperatively, and after 3 , $6,12,18,24$ and 36 months. The box plots show medians and interquartile ranges. ${ }^{*} p<0.05, * * p<0.01$ indicate a statistically significant difference in absolute cell counts of the respective time point to preoperative values. Color images available online at www.liebertpub.com/tea

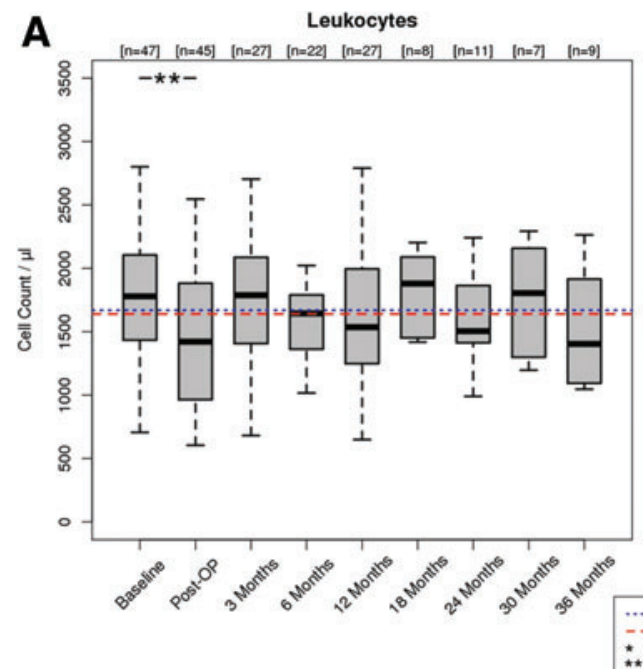

B Lymphocytes
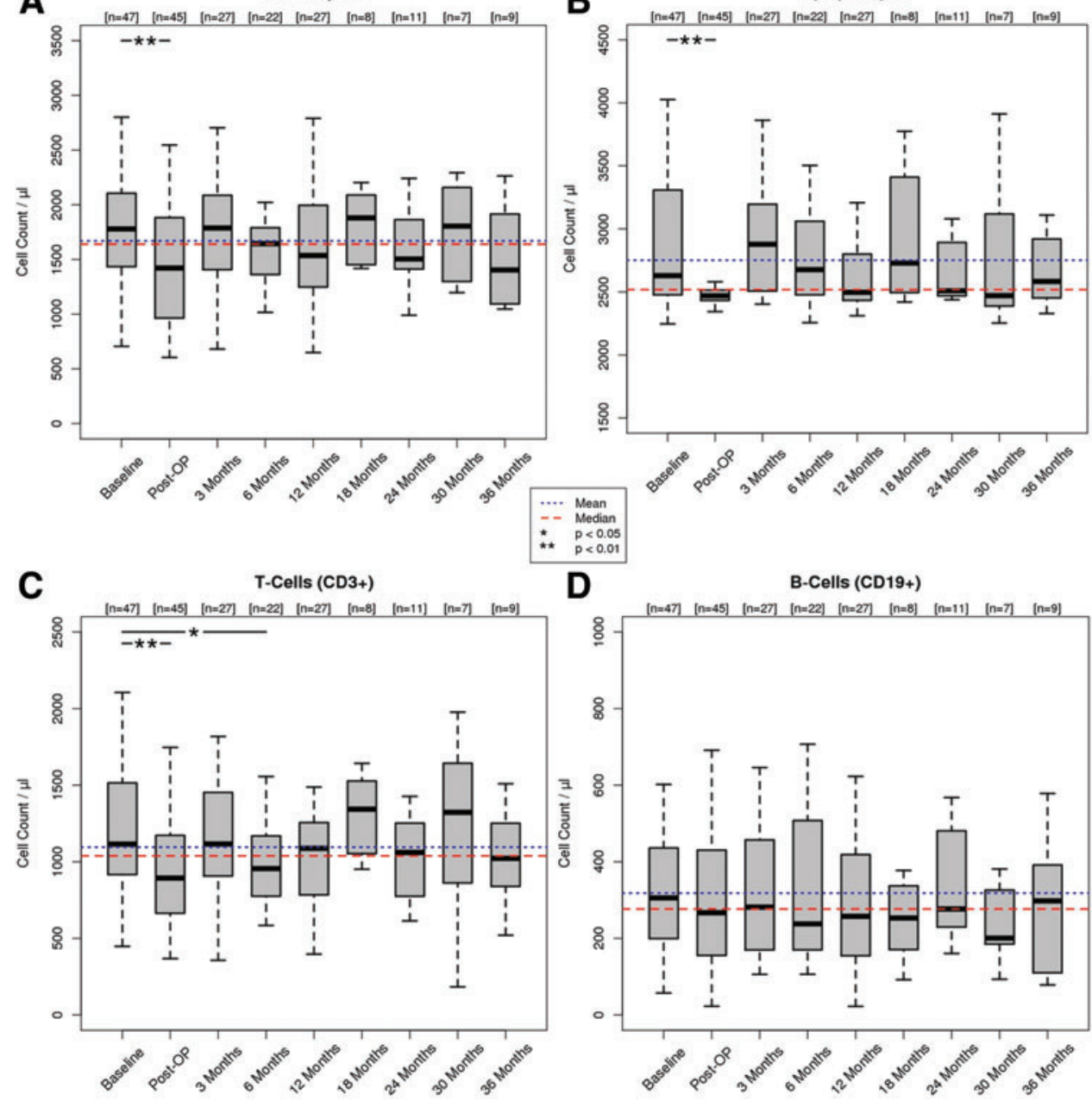


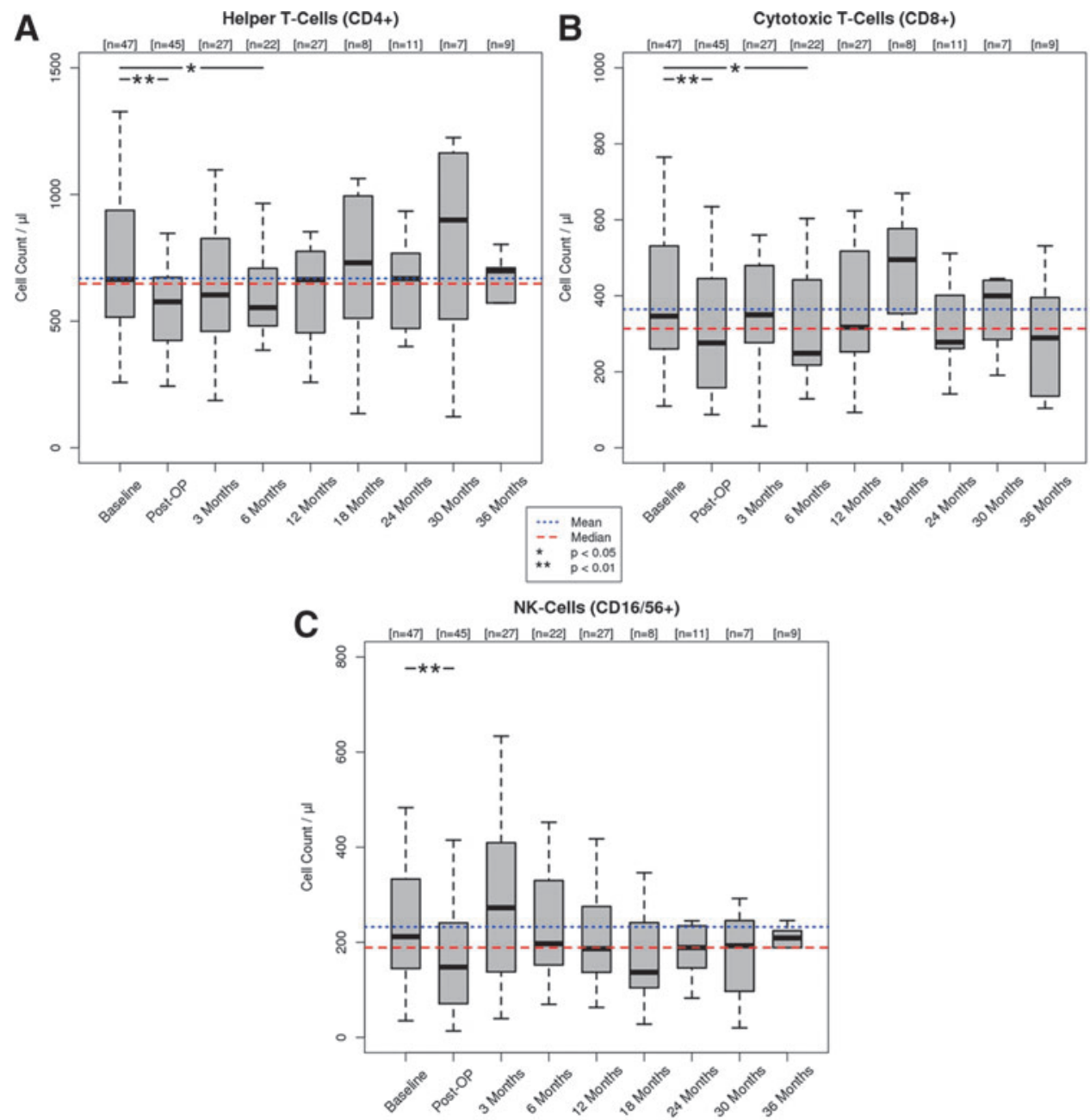

FIG. 3. Systemic cellular immune response during follow up-Part II. Absolute counts of $\mathrm{CD}^{+}{ }^{+}$Helper Tcells (A), $\mathrm{CD}^{+}$Cytotoxic T-Cells (B), and CD16/ $\mathrm{CD} 6^{+}$NK-cells (C) were measured before DPH implantation, directly postoperatively, and after 3, 6, 12, 18, 24 , and 36 months. Box plots show medians and interquartile ranges. ${ }^{*} p<0.05$, $* * p<0.01$ indicate a statistically significant difference in absolute cell counts of the respective time point to preoperative values. Color images available online at www.liebertpub.com/tea

\section{Cellular immune response to $D P H$ valves}

The absolute numbers of white blood cells and lymphocytes, as well as the absolute numbers and percentages of $\mathrm{T}-\left(\mathrm{CD}^{+}\right)$, T helper- $\left(\mathrm{CD} 4^{+}\right)$, cytotoxic T- $\left(\mathrm{CD}^{+}\right)$, B$\left(\mathrm{CD} 19^{+}\right)$, and NK-cells $\left(\mathrm{CD} 16^{+} \mathrm{CD}^{+} 6^{+}\right)$determined by FACS analysis, are shown in Figures 2-4. The mean and median values of the pooled data of all patients are displayed to illustrate cell count variability and to facilitate a comparison.

Immediately after valve implantation, the numbers of white blood cells $(p<0.01)$, lymphocytes $(p<0.001)$, and lymphocyte subsets such as T- $(p<0.01)$, T-helper $(p<0.01)$, T- cytotoxic $(p<0.01)$ and NK-cells $(p<0.01)$ decreased significantly, while the number of B-cells $(p=0.19)$ remained stable. Three months after DPH implantation, an inverse effect was observed and cell numbers normalized for all cell subsets. At 6 months, a temporary, small, nevertheless statistically significant $(p<0.05)$ decrease of $\mathrm{CD}^{+} / \mathrm{CD} 4^{+} /$ $\mathrm{CD}^{+} \mathrm{T}$ cells was seen with normal values for NK-cells and B-cells. Throughout the further study period of up to 36 months, all cell subsets showed no statistically significant alterations. Relative cell counts showed even less alteration within the study period (Fig. 4).

Linear regression models showed no correlation between valvular gradients and cell subsets. However, one patient with a moderate valvular stenosis displayed lymphocytosis and increased NK-cell counts. For this patient, a B- or T-cell proliferative disorder was excluded by analysis of kappaand lambda-light chains as well as the T-cell receptor rearrangement by polymerase-chain reaction.

\section{Discussion}

Cryopreservation is the current standard preservation method for allografts. ${ }^{24,25}$ However, in recent years, there has been a growing body of evidence that cryopreservation may cause serious damage to the endothelial cells, resulting in reduced cell viability. ${ }^{26}$ Moreover, it seems that the process of cryopreservation can cause serious damage to the ECM structures of the valve leaflets, which may be linked to delayed graft failure. ${ }^{27,28}$

The process of cryopreservation itself is complex and difficult to control, as there are several influencing factors, for example, harvesting (warm ischemia), sterilization with antibiotics, freezing which causes fluid shifts and extensive ice crystal formation that damage the ECM, ${ }^{29,30}$ extended storage times, and variability during thawing. In contrast to earlier reports, ${ }^{31}$ cryopreservation does not seem to prevent the activation of the immune system. It is associated with an early infiltration of mononuclear cells and allo-reactive T-cells into valve leaflets. ${ }^{32}$ These chronic inflammatory 
FIG. 4. Systemic cellular immune response during follow up-Part III. Relative counts of $\mathrm{CD}^{+}{ }^{+}$T-cells (A) CD19 ${ }^{+}$B-cells (B), CD4 ${ }^{+}$ Helper T-cells (C), CD16/

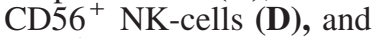
$\mathrm{CD}^{+}$Cytotoxic T-Cells (E) were measured before DPH implantation, directly postoperatively, and after 3,6 , $12,18,24$, and 36 months. The box plots show medians and interquartile ranges. $* p<0.05, * * p<0.01$ when comparing relative cell counts of the respective time point with preoperative values. Color images available online at www .liebertpub.com/tea
A
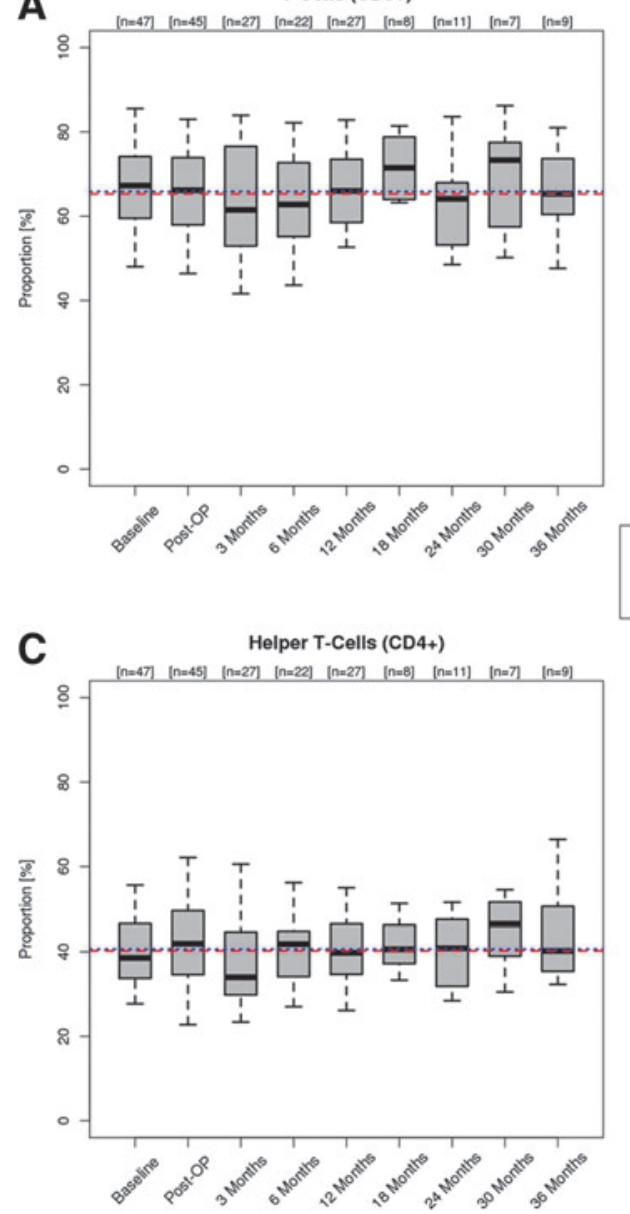

B

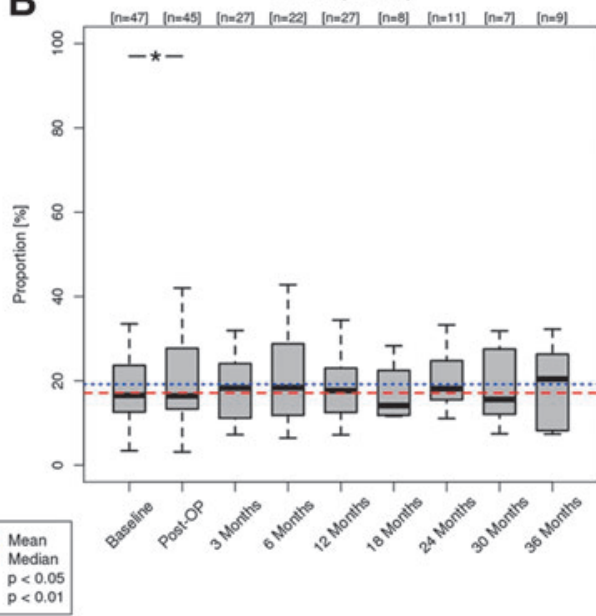

D
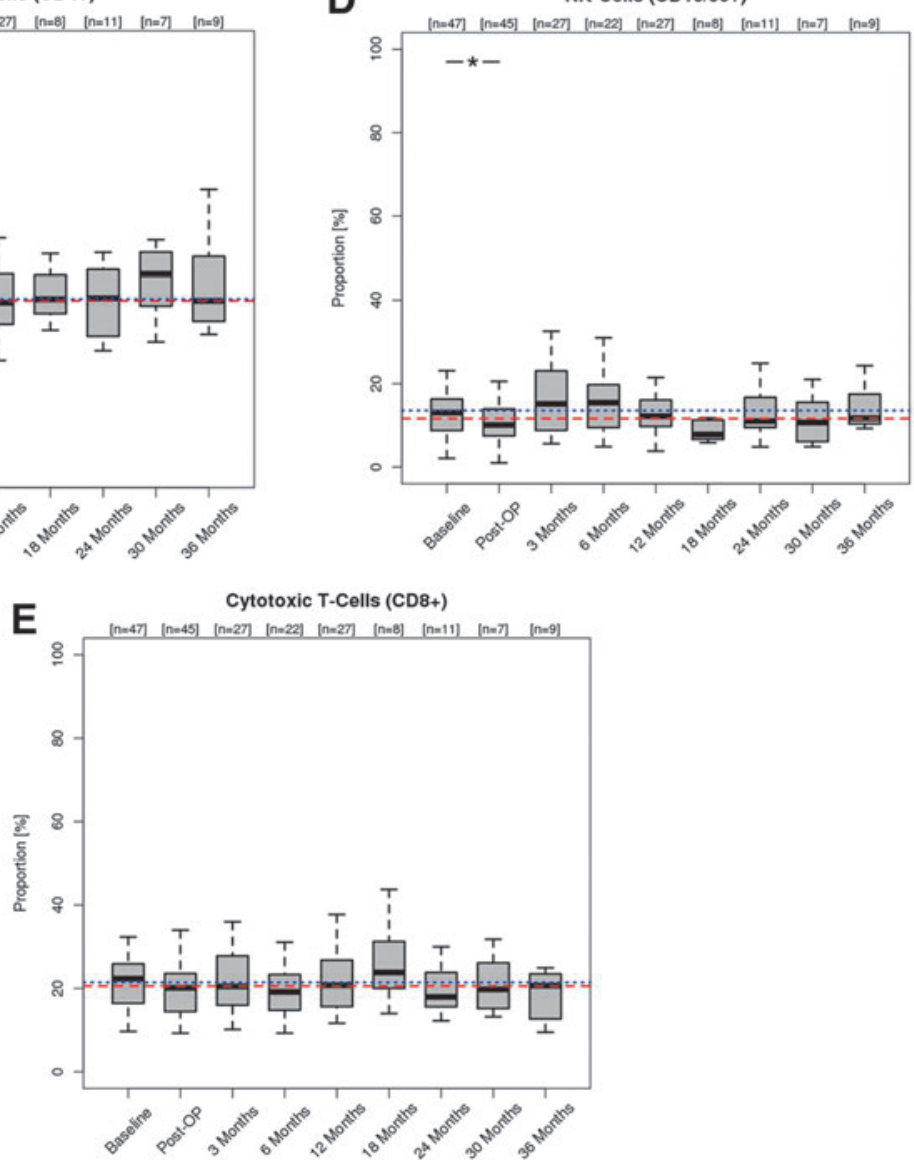

processes predispose cryopreserved valvular allografts to calcification with structural deterioration and dysfunction, resulting in increased re-intervention propensity. With the use of a fresh decellularized human allograft valve, the difficulties discussed earlier as being associated with the process of cryopreservation may be overcome.

Some studies have shown alterations of the mechanical behavior of decellularized pulmonary or aortic valve leaflets, especially an increase in leaflet extensibility and areal strain, reduced stiffness, and decreased flexural modulus. ${ }^{33,34}$ In contrast to other decellularization protocols being tested, the extracellular matrix (ECM) of sodium dodecyl sulfate-treated leaflets resembled that of a native valve with complete maintenance of the basement membrane. ${ }^{9,33}$ Of note, allografts used in these in vitro studies were cryopreserved before undergoing the decellularization procedure. Hemodynamic behavior of fresh decellularized, non-cryopreserved DPH in vivo was favorable in 8 years of follow up within this study, suggesting sufficient mechanical stability.

Using decellularization protocols, which allow an almost complete removal of cells and cellular debris from the graft without affecting the ECM, graft immunogenicity should be 
substantially reduced. Consequently, autologous cells should be able to reseed the graft and stimulate matrix remodeling. ${ }^{35}$

A weakness of our study is the length of follow up, which has so far been limited to 36 months of implantation and this restricted statistical analysis for cell count alterations in the few patients with a longer follow up. Statistical analysis was furthermore hindered by the limited availability of reference data for cell subsets in children and the well-known variability in peripheral cell counts. We compensated for this by analyzing effects across the whole study cohort at every given time point pre- and postoperatively and compared all data for variance with mean and median cell counts of the entire study population.

A temporary decrease in cell numbers shortly after implantation of DPH appears to be a consequence of cardiopulmonary bypass and has been described in this setting. ${ }^{36}$ The initial decrease was followed by normalization to baseline values within 3 months. At 6 months, a temporary decrease of $\mathrm{CD}^{+} / \mathrm{CD} 4^{+} / \mathrm{CD} 8^{+} \mathrm{T}$ cells was seen with normal values for NK-cells and B-cells. Throughout the further study period, all cell subsets showed no statistical significant alterations, which stands in contrast to the results of Wojtalik et al. ${ }^{37}$ In 19 children who received glutaraldehyde fixed xenogeneic valves $\left(\right.$ Contegra ${ }^{\circledR}$ ) for pulmonary valve replacement, they found a significant rise of B-cell percentages between the 3rd and 6th month postoperatively and higher numbers of activated T-cells at 1 year after implantation.

The results obtained in this study support the concept that decellularization can provide a basis for autologous regeneration, as no significant activation of the cellular immune system was observed during short-term follow up, that is, during the period of autologous colonization of the valves. Since early graft failure is predominately a cell-mediated process, the observed lack of early systemic cellular immune response is an important and encouraging finding. This is further augmented by the excellent clinical performance of DPH, which in our view is clearly superior to any available heart valve prosthesis for pulmonary valve replacement in children.

One patient with a half-Asian ethnic background showed signs of conduit degeneration by developing moderate valvular graft stenosis with a peak gradient of $54 \mathrm{mmHg}$ (mean $27 \mathrm{mmHg}$ ) within 18 months and an elevated number of T-, B-, and NK-cell subsets. Although the decellularization procedure has been proved to eliminate $\geq 99 \%$ of donor cells, in rare cases, sporadic cells might survive this process; for example, endothelial cells which carry HLA class I and II molecules that are capable of triggering an immune response. ${ }^{38-40}$ Hawkins et al. observed a transient antibody response to HLA-DR in a few patients who had received the Synergraft ${ }^{\circledR}$ valve, a decellularized cryopreserved allograft. They hypothesised that these antibodies were directed against cells that are highly immunogenic, such as HLA class II-expressing dendritic cells which may be more resistant to the decellularization process. ${ }^{19}$

One may further speculate whether the conduit degeneration in this case may be related to ethnic background as the patient received a DPH of Caucasian origin. It has been shown that there are interethnic cellular immune system differences, for example, in B-cell and NK-cell responses, which may also apply to allogenic (collagen) matrices. ${ }^{41,42}$ Unfortunately, no baseline NK cell count was available in this patient. Regression analysis did not show a relationship between gradient course and cell subset counts, thereby rendering a correlation unlikely in this case.

\section{Limitations}

Our analysis was limited to the amount of cell subsets, for example, regulatory cells were not studied and did not include a further functional analysis of cell sub-cohorts. However, we observed no clinical events, suggesting a regular function of the immune system in our patients.

Our results may not be extrapolated to immune reactions to decellularized aortic allografts, as these allografts are significantly thicker, which may interfere with the decellularization protocols and antigenicity of the ECM. The time to recellularization is expected to be longer in aortic grafts, which may also influence cellular immune reactions.

The observed results in decelluarized fresh allografts may also not be extrapolated to decellularized and, subsequently, cryopreserved allografts, as cryopreservation may interfere with the ECM, thus causing a separate immune response to these valves. ${ }^{43}$

\section{Conclusions}

In our young study cohort of recipients of decellularized fresh pulmonary allografts in the orthotopic position, no significant early activation of the cellular immune response was detected, which corresponded with the excellent midterm clinical and hemodynamic outcomes observed.

\section{Disclosure Statement}

The authors declare that there are no conflicts of interest. A. Haverich holds shares in corlife oHG, a company for the future processing of decellularized allografts, equivalent to those used in this study.

\section{References}

1. Harken, D.E., Soroff, H.S., Taylor, W.J., Lefemine, A.A., Gupta, S.K., and Lunzer, S. Partial and complete prostheses in aortic insufficiency. J Thorac Cardiovasc Surg 40, 744, 1960.

2. Starr, A., and Edwards, M.L. Mitral replacement: clinical experience with a ball-valve prosthesis. Ann Surg 154, 726, 1961.

3. Casselman, F.P., Bots, M.L., Van Lommel, W., Knaepen, P.J., Lensen, R., and Vermeulen, F.E. Repeated thromboembolic and bleeding events after mechanical aortic valve replacement. Ann Thorac Surg 71, 1172, 2001.

4. Forbess, J.M. Conduit selection for right ventricular outflow tract reconstruction: Contemporary options and outcomes. Seminars in thoracic and cardiovascular surgery. Pediatric Card Surg Annu 7, 115, 2004.

5. Levy, R.J. Glutaraldehyde and the calcification mechanism of bioprosthetic heart valves. J Heart Valve Dis 3, 101, 1994.

6. Hawkins, J.A., Breinholt, J.P., Lambert, L.M., Fuller, T.C., Profaizer, T., McGough, E.C., and Shaddy, R.E. Class I and class II anti-hla antibodies after implantation of cryopreserved allograft material in pediatric patients. $J$ Thorac Cardiovasc Surg 119, 324, 2000. 
7. Mohammadi, S., Belli, E., Martinovic, I., Houyel, L., Capderou, A., Petit, J., Planche, C., and Serraf, A. Surgery for right ventricle to pulmonary artery conduit obstruction: risk factors for further reoperation. Eur J Cardiothorac Surg 28, 217, 2005.

8. Curcio, C.A., Commerford, P.J., Rose, A.G., Stevens, J.E., and Barnard, M.S. Calcification of glutaraldehyde-preserved porcine xenografts in young patients. J Thorac Cardiovasc Surg 81, 621, 1981.

9. Lichtenberg, A., Cebotari, S., Tudorache, I., Sturz, G., Winterhalter, M., Hilfiker, A., and Haverich, A. Flow-dependent re-endothelialization of tissue-engineered heart valves. J Heart Valve Dis 15, 287; discussion 293, 2006.

10. Baraki, H., Tudorache, I., Braun, M., Hoffler, K., Gorler, A., Lichtenberg, A., Bara, C., Calistru, A., Brandes, G., Hewicker-Trautwein, M., Hilfiker, A., Haverich, A., and Cebotari, S. Orthotopic replacement of the aortc valve with decellularized allograft in a sheep model. Biomaterials 30, 6240, 2009.

11. Cebotari, S., Tudorache, I., Ciubotaru, A., Boethig, D., Sarikouch, S., Goerler, A., Lichtenberg, A., Cheptanaru, E., Barnaciuc, S., Cazacu, A., Maliga, O., Repin, O., Maniuc, L., Breymann, T., and Haverich, A. Use of fresh decellularized allografts for pulmonary valve replacement may reduce the reoperation rate in children and young adults: early report. Circulation 124, S115, 2011.

12. da Costa, F.D., Costa, A.C., Prestes, R., Domanski, A.C., Balbi, E.M., Ferreira, A.D., and Lopes, S.V. The early and midterm function of decellularized aortic valve allografts. Ann Thorac Surg 90, 18540, 2010.

13. Dohmen, P.M., da Costa, F., Yoshi, S., Lopes, S.V., da Souza, F.P., Vilani, R., Wouk, A.F., da Costa, M., and Konertz, W. Histological evaluation of tissue-engineered heart valves implanted in the juvenile sheep model: Is there a need for in-vitro seeding? J Heart Valve Dis 15, 823, 2006.

14. Cebotari, S., Lichtenberg, A., Tudorache, I., Hilfiker, A., Mertsching, H., Leyh, R., Breymann, T., Kallenbach, K., Maniuc, L., Batrinac, A., Repin, O., Maliga, O., Ciubotaru, A., and Haverich, A. Clinical application of tissue engineered human heart valves using autologous progenitor cells. Circulation 114, I132, 2006.

15. Cicha, I., Ruffer, A., Cesnjevar, R., Glockler, M., Agaimy, A., Daniel, W.G., Garlichs, C.D., and Dittrich, S. Early obstruction of decellularized xenogenic valves in pediatric patients: involvement of inflammatory and fibroproliferative processes. Cardiovasc Pathol 20, 222, 2011.

16. Simon, P., Kasimir, M.T., Seebacher, G., Weigel, G., Ullrich, R., Salzer-Muhar, U., Rieder, E., and Wolner, E. Early failure of the tissue engineered porcine heart valve synergraft in pediatric patients. Eur J Cardiothorac Surg 23, 1002; discussion 1006, 2003.

17. Cebotari, S., Mertsching, H., Kallenbach, K., Kostin, S., Repin, O., Batrinac, A., Kleczka, C., Ciubotaru, A., and Haverich, A. Construction of autologous human heart valves based on an acellular allograft matrix. Circulation 106, I63, 2002.

18. Lichtenberg, A., Tudorache, I., Cebotari, S., Suprunov, M., Tudorache, G., Goerler, H., Park, J.K., Hilfiker-Kleiner, D., Ringes-Lichtenberg, S., Karck, M., Brandes, G., Hilfiker, A., and Haverich, A. Preclinical testing of tissue-engineered heart valves re-endothelialized under simulated physiological conditions. Circulation 114, I559, 2006.
19. Hawkins, J.A., Hillman, N.D., Lambert, L.M., Jones, J., Di Russo, G.B., Profaizer, T., Fuller, T.C., Minich, L.L., Williams, R.V., and Shaddy, R.E. Immunogenicity of decellularized cryopreserved allografts in pediatric cardiac surgery: comparison with standard cryopreserved allografts. J Thorac Cardiovasc Surg 126, 247; discussion 252, 2003.

20. da Costa, F.D., Dohmen, P.M., Duarte, D., von Glenn, C., Lopes, S.V., Filho, H.H., da Costa, M.B., and Konertz, W. Immunological and echocardiographic evaluation of decellularized versus cryopreserved allografts during the ross operation. Eur J Cardiothorac Surg 27, 572, 2005.

21. Hopkins, R.A., Bert, A.A., Hilbert, S.L., Quinn, R.W., Brasky, K.M., Drake, W.B., and Lofland, G.K. Bioengineered human and allogeneic pulmonary valve conduits chronically implanted orthotopically in baboons: hemodynamic performance and immunologic consequences. J Thorac Cardiovasc Surg 145, 1098, 2013.

22. Schenk, S., Kish, D.D., He, C., El-Sawy, T., Chiffoleau, E., Chen, C., Wu, Z., Sandner, S., Gorbachev, A.V., Fukamachi, K., Heeger, P.S., Sayegh, M.H., Turka, L.A., and Fairchild, R.L. Alloreactive T cell responses and acute rejection of single class II MHC-disparate heart allografts are under strict regulation by CD $4+\mathrm{CD} 25+\mathrm{T}$ cells. J Immunol 174, 3741, 2005.

23. Valujskikh, A., Baldwin, W.M., 3rd, and Fairchild, R.L. Recent progress and new perspectives in studying $\mathrm{T}$ cell responses to allografts. Am J Transplant 10, 1117, 2010.

24. Bank, H.L., and Brockbank, K.G. Basic principles of cryobiology. J Card Surg 2, 137, 1987.

25. O’Brien, M.F., Stafford, G., Gardner, M., Pohlner, P., McGiffin, D., Johnston, N., Brosnan, A., and Duffy, P. The viable cryopreserved allograft aortic valve. J Card Surg 2, 153, 1987.

26. Lupinetti, F.M., Tsai, T.T., Kneebone, J.M., and Bove, E.L. Effect of cryopreservation on the presence of endothelial cells on human valve allografts. J Thorac Cardiovasc Surg 106, 912, 1993.

27. Schenke-Layland, K., Madershahian, N., Riemann, I., Starcher, B., Halbhuber, K.J., Konig, K., and Stock, U.A. Impact of cryopreservation on extracellular matrix structures of heart valve leaflets. Ann Thorac Surg 81, 918, 2006.

28. Schenke-Layland, K., Xie, J., Heydarkhan-Hagvall, S., Hamm-Alvarez, S.F., Stock, U.A., Brockbank, K.G., and MacLellan, W.R. Optimized preservation of extracellular matrix in cardiac tissues: implications for long-term graft durability. Ann Thorac Surg 83, 1641, 2007.

29. Brockbank, K.G., Lightfoot, F.G., Song, Y.C., and Taylor, M.J. Interstitial ice formation in cryopreserved homografts: a possible cause of tissue deterioration and calcification in vivo. J Heart Valve Dis 9, 200, 2000.

30. Brockbank, K.G., and Song, Y.C. Morphological analyses of ice-free and frozen cryopreserved heart valve explants. J Heart Valve Dis 13, 297, 2004.

31. Oei, F.B., Stegmann, A.P., Vaessen, L.M., Marquet, R.L., Weimar, W., and Bogers, A.J. Immunological aspects of fresh and cryopreserved aortic valve transplantation in rats. Ann Thorac Surg 71, S379, 2001.

32. Legare, J.F., Lee, T.D., and Ross, D.B. Cryopreservation of rat aortic valves results in increased structural failure. Circulation 102, III75, 2000.

33. Liao, J., Joyce, E.M., and Sacks, M.S. Effects of decellularization on the mechanical and structural properties of the porcine aortic valve leaflet. Biomaterials 29, 1065, 2008. 
34. Converse, G.L., Armstrong, M., Quinn, R.W., Buse, E.E., Cromwell, M.L., Moriarty, S.J., Lofland, G.K., Hilbert, S.L., and Hopkins, R.A. Effects of cryopreservation, decellularization and novel extracellular matrix conditioning on the quasi-static and time-dependent properties of the pulmonary valve leaflet. Acta Biomater 8, 2722, 2012.

35. Goldstein, S., Clarke, D.R., Walsh, S.P., Black, K.S., and O'Brien, M.F. Transpecies heart valve transplant: advanced studies of a bioengineered xeno-autograft. Ann Thorac Surg 70, 1962, 2000.

36. Tajima, K., Yamamoto, F., Kawazoe, K., Nakatani, I., Sakai, H., Abe, T., and Kawashima, Y. Cardiopulmonary bypass and cellular immunity: changes in lymphocyte subsets and natural killer cell activity. Ann Thorac Surg 55, 625, 1993.

37. Wojtalik, M., Mrowczynski, W., Zeromski, J., and Bartkowski, R. Does contegra xenograft implantation evoke cellular immunity in children? Interact Cardiovasc Thorac Surg 2, 273, 2003.

38. Taflin, C., Charron, D., Glotz, D., and Mooney, N. Immunological function of the endothelial cell within the setting of organ transplantation. Immunol Lett 139, 1, 2011.

39. Taflin, C., Favier, B., Baudhuin, J., Savenay, A., Hemon, P., Bensussan, A., Charron, D., Glotz, D., and Mooney, N. Human endothelial cells generate th17 and regulatory $\mathrm{t}$ cells under inflammatory conditions. Proc Natl Acad Sci U S A 108, 2891, 2011.

40. Hoekstra, F., Knoop, C., Aghai, Z., Jutte, N., Mochtar, B., Bos, E., and Weimar, W. Stimulation of immune-competent cells in vitro by human cardiac valve-derived endo- thelial cells. Ann Thorac Surg 60, S131; discussion S133, 1995.

41. Longo, D.M., Louie, B., Putta, S., Evensen, E., Ptacek, J., Cordeiro, J., Wang, E., Pos, Z., Hawtin, R.E., Marincola, F.M., and Cesano, A. Single-cell network profiling of peripheral blood mononuclear cells from healthy donors reveals age- and race-associated differences in immune signaling pathway activation. J Immunol 188, 1717, 2012.

42. Single, R.M., Martin, M.P., Gao, X., Meyer, D., Yeager, M., Kidd, J.R., Kidd, K.K., and Carrington, M. Global diversity and evidence for coevolution of kir and hla. Nat Genet 39, 1114, 2007.

43. Gerson, C.J., Elkins, R.C., Goldstein, S., and Heacox, A.E. Structural integrity of collagen and elastin in synergraft(r) decellularized-cryopreserved human heart valves. Cryobiology 64, 33, 2012.

Address correspondence to:

Samir Sarikouch, MD, PhD

Department of Cardiothoracic, Transplantation and Vascular Surgery

Hannover Medical School Carl-Neuberg-Straße 1 30625 Hannover

Germany

E-mail: sarikouch.samir@mh-hannover.de

Received: May 30, 2013

Accepted: October 10, 2013

Online Publication Date: January 24, 2014 